\title{
Self-assembly studies of allosteric photosynthetic antenna model systems
}

\author{
Paul J. Thomassen, ${ }^{a}$ Jantien Foekema, ${ }^{a}$ Ribera Jordana i Lluch, ${ }^{a}$ Pall Thordarson, ${ }^{b}$ \\ Johannes A. A. W. Elemans, ${ }^{a}$ Roeland J. M. Nolte ${ }^{* a}$ and Alan E. Rowan ${ }^{* c}$
}

Received (in Durham, UK) 1st August 2005, Accepted 25th November 2005

First published as an Advance Article on the web 20th December 2005

DOI: $10.1039 / \mathbf{b 5 1 0 9 6 8 j}$

In this paper allosteric interactions are employed to enhance electron transfer in a pseudorotaxane system. Binding of an axial ligand (tbpy) to an electron donating mono-cavity appended zinc porphyrin $(\mathbf{Z n P})$ increases the complexation strength to an electron accepting monosubstituted bipyridine, resulting in a more pronounced electron transfer process after excitation of the zinc porphyrin. Binding constants are presented for this host and different mono-substituted bipyridine guests.

\section{Introduction}

One of the most fundamental steps in photosynthesis is photoinduced charge separation, which takes place in the photosynthetic reaction centre. ${ }^{1}$ Here, complex arrays of chromophores trap solar energy and convert it into chemical energy. ${ }^{2}$ The study of electron and energy transfer within synthetic chromophoric arrays has therefore been of great biological relevance and hence a large number of covalently-linked porphyrin-containing donor-acceptor systems have been synthesised and their photodynamic properties have been studied in great detail. ${ }^{3,4}$ In Nature however, the chromophores are all non-covalently attached to a protein scaffold, which holds them at the correct separation and orientation for the occurrence of fast, unidirectional and efficient electron transfer (ET). This aspect of the photosynthetic antenna has also been extensively mimicked. ${ }^{5}$

In contrast to the above, the use of cooperative and allosteric interactions for the self-assembly of photo-active complexes has so far been largely unexplored, although it has been shown that the exploitation of cooperative coordination reactions between chromophores has major advantages over employing hydrogen-bonding or standard non-cooperative coordination chemistry. ${ }^{6}$

A special case of cooperativity, in which a binding event in a multivalent host at one site causes a discrete, reversible alteration in the structure of the host at a remote binding site, is called allosterism. ${ }^{7}$ Allosteric interactions can be both positive and negative, and can act between a host and identical guests (homotropic), or between a host and different guests (heterotropic).

\footnotetext{
${ }^{a}$ Department of Organic Chemistry, Institute for Molecules and Materials, Radboud University Nijmegen, Toernooiveld 1, 6525 ED Nijmegen, The Netherlands. E-mail: R.Nolte@science.ru.nl; Fax: (+31)24-3653393; Tel: (+31)24-3652143

${ }^{b}$ Australian Key Centre for Microscopy and Microanalysis/School of Chemistry, The University of Sydney, Madsen Building, NSW 2006 Sydney, Australia

${ }^{c}$ Department of Molecular Materials, Institute for Molecules and Materials, Radboud University Nijmegen, Toernooiveld 1, 6525 ED Nijmegen, The Netherlands.E-mail: A.Rowan@science.ru.nl; Fax: (+31)24-3653393; Tel: $(+31) 24-3652323$
}

Recently our group has developed several porphyrin-based host-guest systems that display unique allosteric effects. ${ }^{8}$ One of these systems was based on a monocavity-appended zinc porphyrin host $\mathbf{Z n P}$ that has a strong affinity for both viologen guests (V) and axial ligands and exhibits a positive heterotropic binding behaviour. ${ }^{8 b, 9}$

We have demonstrated that these allosteric interactions can be employed in the self-assembly of host-guest systems to increase the percentage ratio of the host-guest complex in solution relative to their separate, uncomplexed components, a form of allosteric magnification.

As a continuation of this research, we present here two new model antenna systems, which are constructed with the help of allosteric interactions. Fig. 1a shows the molecular components used in this study: ZnP and axial ligand 4-tert-butylpyridine (tbpy), non-methylated-4,4'-bipyridine appended Auporphyrin (AuP-bipy), and its analogue with four non-methylated-4,4'-bipyridines covalently attached to the Au-porphyrin (AuP-(bipy) $)_{4}$. Self-assembly of these components in solution results in an equilibrium mixture containing the pseudo-rotax-

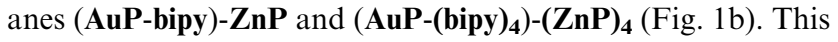
equilibrium can be driven to the full complex by the addition of a ligand (tbpy) that can be axially bound to zinc, resulting in pseudo-rotaxanes (AuP-bipy)-ZnP-tbpy and (AuP-(bipy) 4 )(ZnP) $)^{-}$(tbpy) $)_{4}$.

\section{Results and discussion}

\section{Model studies on mono-substituted bipyridines}

In earlier work it has been demonstrated that $\mathbf{Z n P}$ binds viologen derivatives very strongly in its cavity $\left(K_{\mathrm{ass}}>10^{5}\right.$ $\mathrm{M}^{-1}$ ) and that the bulky ligand tbpy coordinates simultaneously to the porphyrin zinc ion at the outside of the cavity (Fig. 2). ${ }^{10}$

To establish whether mono-substituted bipyridines would also display strong binding inside $\mathbf{Z n P}$, three different model compounds of this class were synthesised, M-bipy, P-bipy and T-bipy (Fig. 3).

The simplest of these compounds, M-bipy, is complexed in the cavity of $\mathbf{Z n P}$ at a concentration of $10^{-3} \mathrm{M}$ in $\mathrm{CDCl}_{3}$ / $\mathrm{CD}_{3} \mathrm{CN}=1: 1(\mathrm{v} / \mathrm{v})$, according to ${ }^{1} \mathrm{H}$ NMR measurements. 
(a)

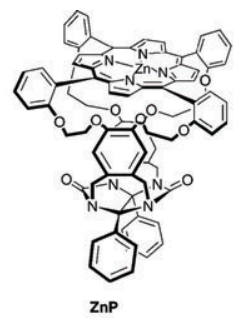

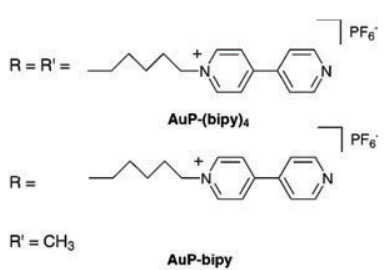

(b)

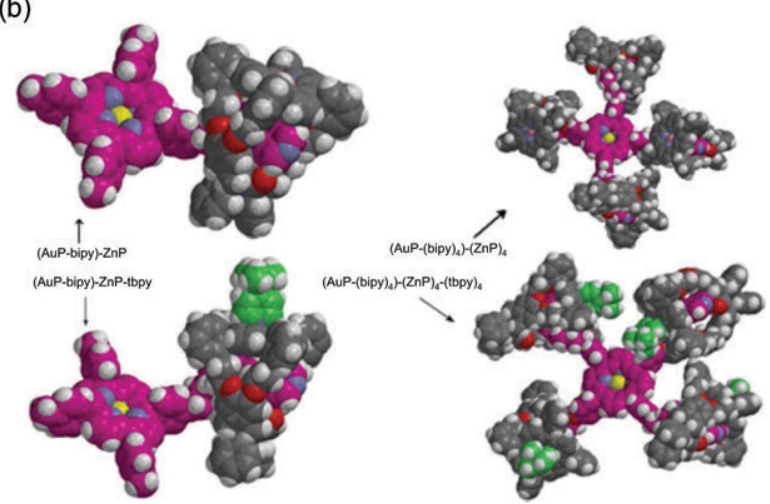

Fig. 1 (a) Molecules used in the construction of antenna systems. (b) PM3 optimised structures of (AuP-bipy)-ZnP, (AuP-bipy)-ZnP-tbpy and MMFF optimised structures of (AuP-(bipy) $\left.)_{4}\right)-(\mathbf{Z n P})_{\mathbf{4}}$ and (AuP-(bipy) $\left.)_{4}\right)-(\mathrm{ZnP})_{4}$-(tbpy) . $^{-}$

Both the crown ether proton signals of $\mathbf{Z n P}$ and the proton signals of the aromatic side-walls are severely broadened and shifted upfield by $0.3 \mathrm{ppm}$ (Table 1 , for the proton numbering see Fig. 4). The broadening is caused by the asymmetry of the
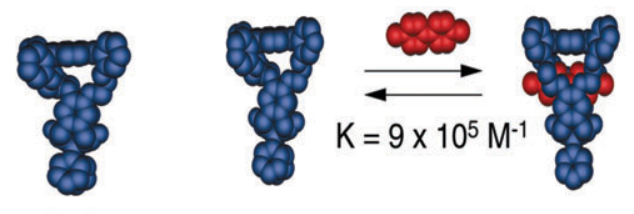

$$
\mathrm{ZnP}
$$
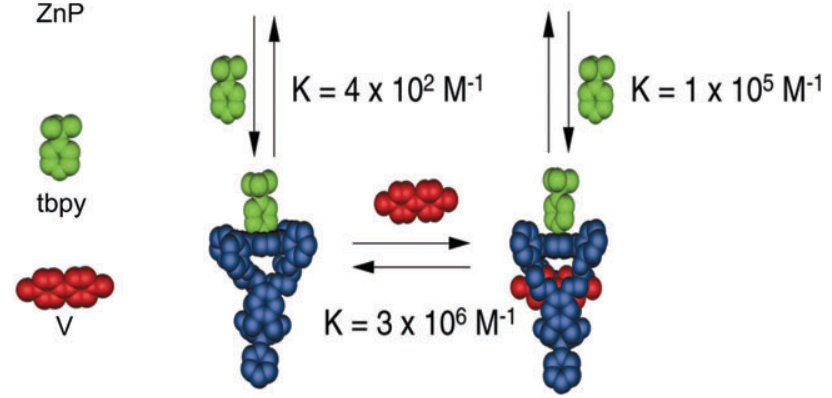

Fig. 2 Schematic representation summarizing the possible complexes of $\mathbf{Z n P}$ with tbpy and dimethyl-viologen, together with the relevant binding constants.

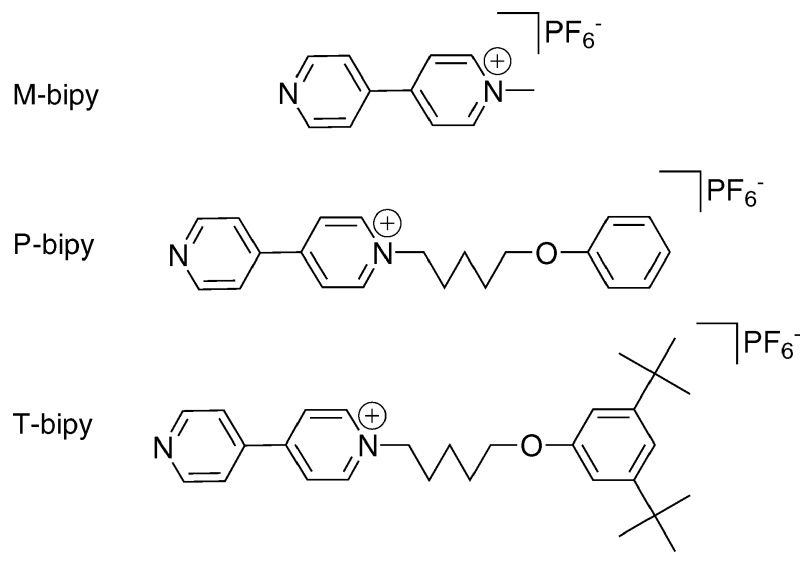

Fig. 3 Mono-substituted bipyridines.

host-guest complex and a rapid exchange between the free species and the complex. This complexation-decomplexation process is too rapid to be frozen out using NMR and hence a broad average signal is observed. The proton signals of M-bipy were not detectable, seemingly due to coalescence of the signals of the bound and unbound species.

A fluorescence titration, in which M-bipy was added to $\mathbf{Z n P}$, revealed a quenching of the fluorescence of the zinc porphyrin at $605 \mathrm{~nm}$ (excitation $426 \mathrm{~nm}$ ) of $6 \%$ after the addition of 1 equivalent and of $97 \%$ after the addition of 100 equivalents of the guest (Fig. 5, Table 2). From UV-Vis titrations, a binding constant $K_{\mathrm{a}}=7.5 \times 10^{4} \mathrm{M}^{-1}$ was calculated. At a ratio of $\mathbf{Z n P} / \mathbf{M}$-bipy $=1: 1$, this value indicates an occupation of the host cavity of $7 \%$ at a concentration of $10^{-6} \mathrm{M}$ and of $95 \%$ at a ratio of $1: 100$, which corresponds well with the observed quenching of 6 and $97 \%$ at both titration points. The observed fluorescence behaviour confirms the conclusion by Milgrom et al. that mono-substituted bipyridines, just like viologens, are effective quenchers of $\mathrm{Zn}$ porphyrin fluorescence due to fast ET from the porphyrin to the mono-alkylated bipyridinium unit, which is tentatively attributed to a weak ligation to the zinc ion. ${ }^{11}$

In agreement with observations by Milgrom et al. no evidence for axial binding was found. A $1: 1$ mixture of M-bipy and Zn tetrakis-meso-p-toluyl-porphyrin (ZnTTP) showed no complexation at $10^{-3} \mathrm{M}$ concentration in $\mathrm{CDCl}_{3} /$ $\mathrm{CD}_{3} \mathrm{CN}=1: 1(\mathrm{v} / \mathrm{v})$, according to ${ }^{1} \mathrm{H}$ NMR. This indicates that binding inside the cavity of $\mathbf{Z n P}$ is the predominant binding mode. A fluorescence titration in which M-bipy was added to ZnTTP gave 13\% quenching of fluorescence after the addition of 500 eq of M-bipy (Table 2). This may be attributed to a solvent effect, given the fact that addition of M-bipy results in an increase in the ionic strength and therefore activity of the solution, possibly leading to a different association constant for the binding of acetonitrile to the zinc ion. Alternatively and perhaps more plausibly, a binding mode parallel to the porphyrin plane through $\pi-\pi$ interactions, in contrast to axial binding, could be responsible for the observed quenching. However, this low value for the observed quenching does highlight the ineffectiveness of mono-substituted bipyridines to quench the excited state of the zinc porphyrin, when axial binding is the only binding mode available. 
Table 1 Induced chemical shifts ${ }^{a}(\Delta \delta, \mathrm{ppm})$ of proton signals upon binding of mono-substituted bipyridine units in the cavity of $\mathbf{Z n P}$

\begin{tabular}{|c|c|c|c|c|c|c|c|c|c|c|}
\hline & $\alpha$ & $\beta$ & $\alpha^{\prime}$ & $\beta^{\prime}$ & $\gamma$ & 1a & $2 \mathrm{a}$ & $2 b$ & $3 a$ & $3 b$ \\
\hline$\overline{\text { Ref. }^{b}}$ & 8.83 & 8.27 & 8.74 & 7.71 & 4.56 & 6.20 & 3.52 & 3.23 & 4.17 & 4.07 \\
\hline M-bipy & - & - & - & - & - & $-0.3^{c}$ & $-0.3^{c}$ & $-0.3^{c}$ & $-0.3^{c}$ & $-0.3^{c}$ \\
\hline P-bipy & -5.07 & -3.95 & -2.97 & -3.83 & -1.43 & -0.17 & -0.14 & -0.10 & 0.14 & 0.01 \\
\hline T-bipy & -5.14 & -4.00 & -2.98 & -3.84 & -1.44 & -0.16 & $\begin{array}{l}-0.12^{d} \\
-0.39^{e}\end{array}$ & $\begin{array}{l}-0.42^{d} \\
-0.85^{e}\end{array}$ & $\begin{array}{r}0.15^{d} \\
-0.02^{e}\end{array}$ & $\begin{array}{l}-0.23^{d} \\
-0.23^{e}\end{array}$ \\
\hline AuP-bipy & -5.37 & -4.14 & -2.97 & -3.76 & -1.42 & -0.06 & $\begin{array}{l}-0.06^{d} \\
-0.32^{e}\end{array}$ & $-0.36^{d}$ & $\begin{array}{r}0.23^{d} \\
-0.03^{e}\end{array}$ & $\begin{array}{l}-0.30^{\circ} \\
-0.30^{e}\end{array}$ \\
\hline AuP-(bipy) ${ }_{4}$ & - & - & -2.94 & - & -1.41 & 0.03 & 0.01 & -0.08 & 0.24 & 0.09 \\
\hline
\end{tabular}

${ }^{a} \mathrm{CDCl}_{3} / \mathrm{CD}_{3} \mathrm{CN}=1: 1(\mathrm{v} / \mathrm{v}) .[\mathrm{ZnP}]=$ [guest] $=10^{-3} \mathrm{M} . T=298 \mathrm{~K}$. A shift with a negative value represents an upfield shift and vice versa. ${ }^{b}$ Proton signals of $\mathbf{Z n P}$ or the respective guests in the uncomplexed form. ${ }^{c}$ Broad peaks. ${ }^{d}$ Proton signals from the front side of the $\mathbf{Z n P}$ host. ${ }^{e}$ Proton signals from the back side of the $\mathbf{Z n P}$ host. ${ }^{f}$ The signal can not be distinguished from the $\mathrm{H}_{2} \mathrm{O}$ signal.

To investigate the effect of the presence of an alkyl chain spacer, compound P-bipy was synthesised. ${ }^{1} \mathrm{H}$ NMR measurements at a concentration of $10^{-3} \mathrm{M}$ in $\mathrm{CDCl}_{3} / \mathrm{CD}_{3} \mathrm{CN}=1: 1$ $(\mathrm{v} / \mathrm{v})$ again showed that the guest was bound into the cavity of the $\mathbf{Z n P}$ host, since large upfield shifts were observed for the signals of the bipyridine protons (Table 1). Apparently the alkyl chain spacer slows down the exchange process between bound and unbound species, allowing for the detection of clear mono-substituted bipyridine proton signals. From the observed chemical shifts one can conclude that the P-bipy guest is bound asymmetrically in the $\mathbf{Z n P}$ host. The porphyrin is shifted towards the alkyl chain (the induced chemical shift of the $\alpha$-protons is bigger than that of the $\alpha^{\prime}$-protons), which is in agreement with the known affinity of porphyrin clips for alkyl chains. ${ }^{10 b}$

From UV-Vis titrations a binding constant $K_{\mathrm{a}}=2.2 \times 10^{5}$ $\mathrm{M}^{-1}$ was determined. The slower complexation-decomplexation process is seemingly the result of this increase in binding constant when compared to M-bipy. The addition of $10 \mathrm{eq}$ of P-bipy to $\mathbf{Z n P}$ resulted in the quenching of the fluorescence emission of $66 \%$, which corresponds perfectly with the calculated $67 \%$ occupation of the host at a concentration of $10^{-6} \mathrm{M}$ (Table 2).

When the UV-Vis titration of $\mathbf{Z n P}$ with $\mathbf{P}$-bipy was carried out in the presence of 500 eq tbpy, the $K_{\mathrm{a}}$-value increased to $6.8 \times 10^{5} \mathrm{M}^{-1}$ as a result of allosteric effects. ${ }^{8 b}$ In this case, the quenching of the fluorescence of $\mathbf{Z n P}$ after addition of 10 eq P-bipy had risen, due to 'allosteric quenching magnification'
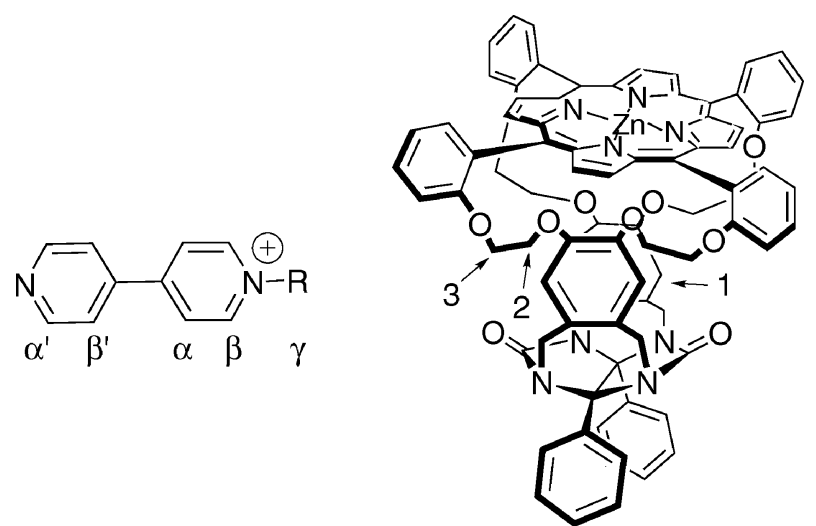

Fig. 4 Proton numbering of $\mathbf{Z n P}$ and mono-substituted bipyridine molecules.
(AQM) to $84 \%$, which again corresponds well with the calculated $86 \%$ complexation at this concentration.

In a reverse approach, the addition of $500 \mathrm{eq}$ of tbpy to a 1: 1 mixture of $\mathbf{Z n P}$ and $\mathbf{P}$-bipy in $\mathrm{CHCl}_{3} / \mathrm{CH}_{3} \mathrm{CN}=1: 1(\mathrm{v} / \mathrm{v})$, resulted in an AQM of the initial fluorescence by an additional $46 \%$. By using the respective binding constants, an increase in population of the host-guest complex from $16 \%$ to $32 \%$ can be calculated. The addition of 500 eq tbpy to a solution of exclusively $\mathbf{Z n P}$ resulted in a fluorescence quenching of only $10 \%$.

As a third reference compound, T-bipy was investigated, which has a 3,5-di-tert-butyl-benzene stopper group which is bulky enough that $\mathbf{Z n P}$ can only bind on the bipyridine unit from one side (Fig. 1). ${ }^{1} \mathrm{H}$ NMR experiments at a concentration of $10^{-3} \mathrm{M}$ in $\mathrm{CDCl}_{3} / \mathrm{CD}_{3} \mathrm{CN}=1: 1(\mathrm{v} / \mathrm{v})$ showed a similar binding geometry as the one found for P-bipy (Table 1). Again, the zinc porphyrin is complexed asymmetrically above the bipyridine unit and shifted towards the alkyl chain. Furthermore, the crown ether signals of $\mathbf{Z n P}$ are split up into two sets of signals, indicating a 'front'- and a 'back'-side. The front side we have defined as the side of the $\mathbf{Z n P}$ host where the alkyl chain protrudes from the cavity. Also the signal of the $\beta$-pyrrolic protons not above the cavity is split into two signals for both sides because of the loss of symmetry in the host upon binding of an unsymmetric guest.

UV-Vis titrations in which T-bipy was added to $\mathbf{Z n P}$ showed an increase in binding constant, compared to P-bipy, to $K_{\mathrm{a}}=$ $3.6 \times 10^{5} \mathrm{M}^{-1}$. As can be seen from Table 2, the total zinc porphyrin fluorescence quenching by this guest is also a little higher than the quenching by P-bipy.

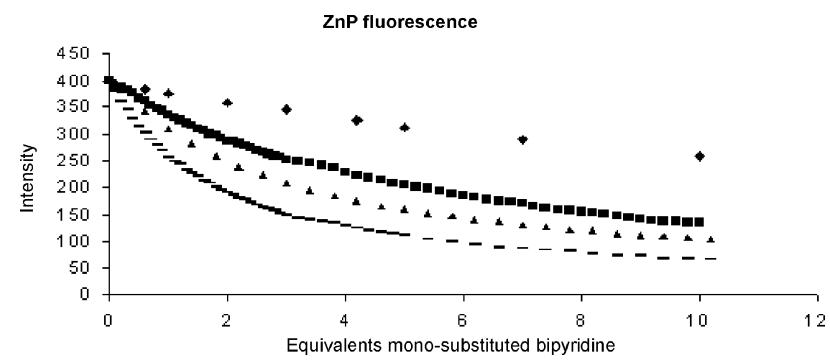

Fig. 5 Fluorescence quenching of $\mathbf{Z n P}$ by M-bipy, P-bipy and P-bipy in the presence of 500 eq tbpy. $\mathrm{CHCl}_{3} / \mathrm{CH}_{3} \mathrm{CN}=1: 1(\mathrm{v} / \mathrm{v}) . T=298$ $\mathrm{K}$. Excitation wavelength $=426 \mathrm{~nm}$. Emission wavelength $=605 \mathrm{~nm}$. $[\mathbf{Z n P}]=10^{-6} \mathrm{M} . \bullet \mathbf{Z n P}+$ M-bipy; $\mathbf{Z n P}+\mathbf{P}$-bipy; $-\mathbf{Z n P} / \mathbf{t b p y}+$ P-bipy; $\triangle$ ZnP + T-bipy. 
Table 2 Quenching $\left(\mathrm{Q}_{\mathrm{F}}\right)$ of $\mathrm{Zn}$ porphyrin $(\mathrm{P})$ fluorescence ${ }^{a}$ and calculated association constants $K_{\mathrm{a}}$ and free energies $\Delta G$ to various ligands $\mathrm{L}$ in the absence and presence of substrates $\mathrm{R}$

\begin{tabular}{|c|c|c|c|c|c|c|c|c|}
\hline $\mathrm{P}$ & $\mathrm{L}$ & $\mathrm{R}$ & $\mathrm{Q}_{\mathrm{F}}(1 \mathrm{eq})(\%)$ & $\mathrm{Q}_{\mathrm{F}}(10 \mathrm{eq})(\%)$ & Total $\mathrm{Q}_{\mathrm{F}}(\%)$ & $K_{\mathrm{ass}}^{b} / \mathrm{M}^{-1}$ & $\Delta G / \mathrm{kJ} \mathrm{mol}^{-1}$ & $\mathrm{Q}_{\mathrm{F}}{ }^{c}$ \\
\hline $\mathrm{ZnP}$ & M-bipy & & 6 & 35 & 97 (100 eq) & $7.5 \times 10^{4}$ & -28 & \\
\hline $\mathrm{ZnP}$ & P-bipy & & 19 & 66 & & $2.2 \times 10^{5}$ & -30 & \\
\hline $\mathrm{ZnP}$ & P-bipy & tbpy & 36 & 84 & & $6.8 \times 10^{5}$ & -33 & 1.9 \\
\hline $\mathrm{ZnP}$ & T-bipy & & 22 & 74 & & $3.6 \times 10^{5}$ & -32 & \\
\hline $\mathrm{ZnP}$ & tbpy & & & & $10(500 \mathrm{eq})$ & $4 \times 10^{2}$ & -15 & \\
\hline $\mathrm{ZnP}$ & tbpy & P-bipy & & & $46^{d}(500 \mathrm{eq})$ & $1.9 \times 10^{3}$ & -19 & \\
\hline ZnTTP & M-bipy & & & 3 & $13(500 \mathrm{eq})$ & $7.6 \times 10^{3}$ & -22 & \\
\hline $\mathrm{ZnP}$ & AuP-bipy & & 17 & 75 & & $3 \times 10^{5}$ & -31 & \\
\hline $\mathrm{ZnP}$ & AuP-bipy & tbpy & 34 & 90 & & $8 \times 10^{5}$ & -34 & 2.0 \\
\hline $\mathrm{ZnP}$ & tbpy & AuP-bipy & & & $14^{d}(500 \mathrm{eq})$ & & & \\
\hline $\mathrm{ZnP}$ & AuP-(bipy) ${ }_{4}$ & & $20^{e}$ & $88^{e}$ & & $7 \times 10^{5}$ & -33 & \\
\hline $\mathrm{ZnP}$ & AuP-(bipy) & tbpy & $18^{e}$ & $83^{e}$ & & $4 \times 10^{5}$ & -32 & 0.90 \\
\hline $\mathrm{ZnP}$ & tbpy & AuP-(bipy) ${ }_{4}$ & & & $10^{d}$ & & & \\
\hline
\end{tabular}

${ }^{a}$ Excitation wavelength $=426 \mathrm{~nm}$. Emission wavelength $=560 \mathrm{~nm} . T=298 \mathrm{~K} . \mathrm{CHCl}_{3} / \mathrm{CH}_{3} \mathrm{CN}=1: 1(\mathrm{v} / \mathrm{v}) .[\mathrm{ZnP}]=[\mathbf{Z n T T P}]=10^{-6}$ M. ${ }^{b}$ Association constants obtained from fluorescence data have been compared with the reported $K_{\text {ass }}$-values determined from UV-Vis data. They were found to be similar and are therefore not mentioned. In the calculation of the association constants it was assumed that the quantum yield of the host and of the host-guest complexes are the same. ${ }^{c}$ Allosteric quenching magnification factor: (observed percentage zinc porphyrin quenching by 1 eq of guest in the absence of tbpy)/(observed percentage zinc porphyrin quenching by 1 eq of guest in the presence of 500 eq tbpy). ${ }^{d}$ Observed percentage of the quenching of zinc porphyrin fluorescence relative to the fluorescence in the absence of tbpy. ${ }^{e}$ Equivalents of mono-substituted bipyridine guest (corresponds to $\left.4 \times[\text { AuP-(bipy) })_{4}\right)$.

\section{Gold porphyrin antenna systems}

Numerous covalent free base and zinc porphyrin-viologen arrays have been studied in the literature, and it was found that attached viologens are efficient quenchers of both the excited singlet and triplet state of the central porphyrin. ${ }^{12} \mathrm{~A}$ through-solvent ET process from the central porphyrin to viologen was cautiously suggested. ${ }^{12 c, d}$ We presume that such a process occurs in our system as well.

The insertion of gold into the central porphyrin enables circumvention of the problem of overlapping absorption spectra that is often encountered in donor-acceptor free-base porphyrin and zinc porphyrin systems, enabling one porphyrin type to be selectively excited. ${ }^{13}$ The use of gold porphyrins as electron acceptors for electron-donating photo-excited zinc porphyrins has been well described in the literature. ${ }^{14}$ More recently the precise process of electron transfer has been questioned. ${ }^{14 d}$

We have synthesised the porphyrin-bipyridine arrays analogous to the procedure described in the literature. ${ }^{12 a, b}$ Gold was inserted into the free base compounds by refluxing them in the presence of $\mathrm{KAuCl}_{4}$ and $\mathrm{NaOAc}$ in acetic acid. ${ }^{15}$

The UV-Vis absorption spectrum of a $1: 1$ mixture of $\mathbf{Z n P}$ and AuP-bipy in $\mathrm{CHCl}_{3} / \mathrm{CH}_{3} \mathrm{CN}=1: 1(\mathrm{v} / \mathrm{v})$ at a concentration of $10^{-6} \mathrm{M}$ is almost a superposition of the UV-Vis spectra of the respective pure compounds (Fig. 6). However, the Soret band of $\mathbf{Z n P}$ is observed to be red-shifted by $3 \mathrm{~nm}$, because at this concentration a percentage of the bipyridine units of AuPbipy is complexed inside $\mathbf{Z n P}$. The absence of large shifts or appearance of new peaks proves that there is no ground-state electronic interaction between the two components.

The ${ }^{1} \mathrm{H}$ NMR spectrum of a $1: 1$ mixture of AuP-bipy and $\mathbf{Z n P}$ in $\mathrm{CDCl}_{3} / \mathrm{CD}_{3} \mathrm{CN}=1: 1(\mathrm{v} / \mathrm{v})$ shows a binding mode similar to $\mathbf{Z n P}$ and T-bipy. Large upfield shifts for the bipyridine protons are observed and again a split between signals from the $\beta$-pyrrolic protons not above the cavity and the crown ether protons into a set for the front side and one for the back side of $\mathbf{Z n P}$ (see Fig. 7). As before, the front side of the host molecule has been defined as the side from which the alkyl chain protrudes.

The addition of AuP-bipy to a solution of $\mathbf{Z n P}$ in $\mathrm{CHCl}_{3} /$ $\mathrm{CH}_{3} \mathrm{CN}=1: 1(\mathrm{v} / \mathrm{v})$ results in quenching of the zinc

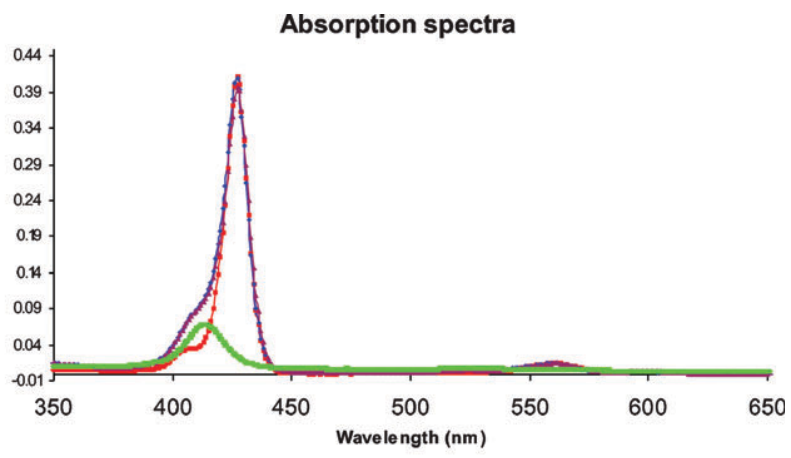

Fluorescence spectra

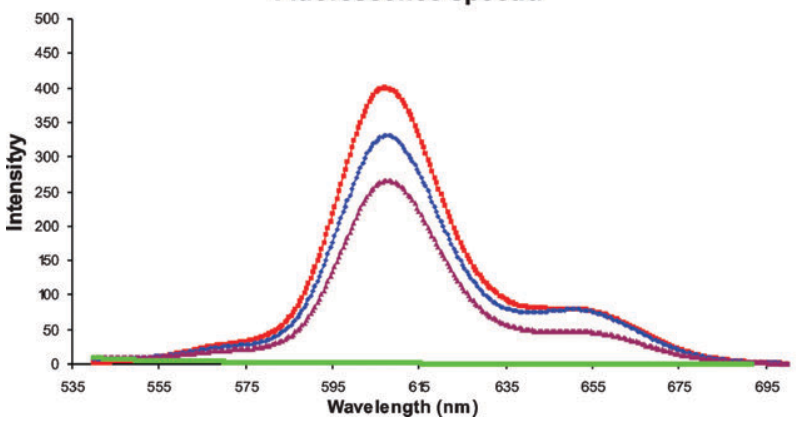

Fig. 6 UV-Vis absorption and fluorescence emission spectra of ZnP and AuP-bipy and of a 1:1 mixture in the absence of and in the presence of 500 eq tbpy. $\mathrm{CHCl}_{3} / \mathrm{CH}_{3} \mathrm{CN}=1: 1(\mathrm{v} / \mathrm{v}) . T=298 \mathrm{~K}$. Excitation $(\mathbf{Z n P})=426 \mathrm{~nm}$; excitation (AuP-bipy) $=411 \mathrm{~nm}$. ZnP (UV-Vis): 426, $545 \mathrm{~nm}$; (fluor) = $605 \mathrm{~nm}$. AuP-bipy (UV-Vis): 411, 521 $\mathrm{nm}$; no fluorescence emission detected. $[\mathbf{Z n P}]=[\mathbf{A u P}-\mathbf{b i p y}]=10^{-6} \mathrm{M}$. ZnP (red); ZnP + AuP-bipy (blue); ZnP + AuP-bipy + tbpy (purple); AuP-bipy (green). 


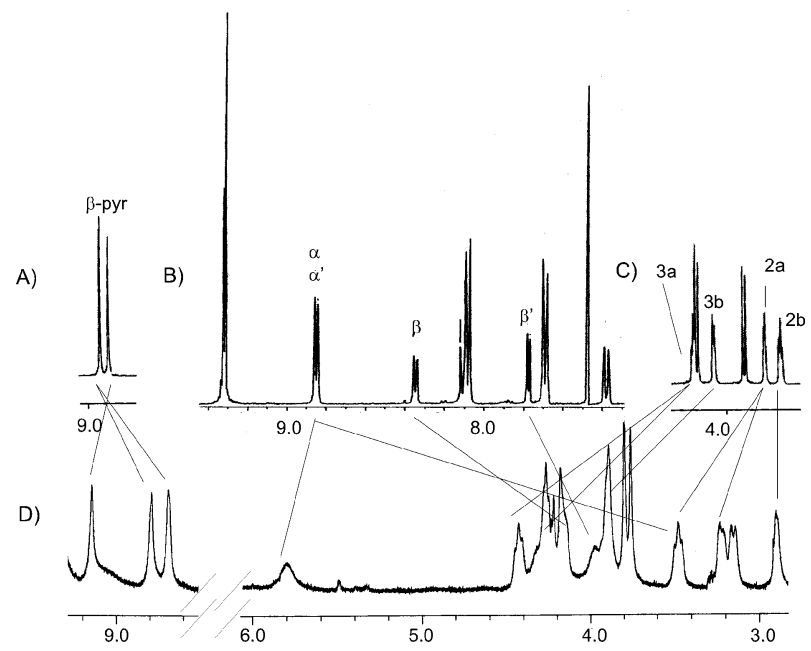

Fig. $7{ }^{1} \mathrm{H}$ NMR spectra (400.15 MHz, $\mathrm{CDCl}_{3} / \mathrm{CD}_{3} \mathrm{CN}=1: 1(\mathrm{v} / \mathrm{v})$, $298 \mathrm{~K}$ ). (A) $\beta$-pyrrolic region of ZnP. (B) Aromatic region of AuP-bipy. (C) Crown ether region of ZnP. (D) Partial spectrum of (AuP-bipy)-ZnP.

porphyrin fluorescence at $605 \mathrm{~nm}$, after excitation at $426 \mathrm{~nm}$. This quenching increases from $17 \%$ at a $1: 1$ host-guest ratio to $75 \%$ at a ratio of $1: 10$ (Fig. 8 , Table 2 ). Repetition of this titration in the presence of 500 eq of tbpy, resulted in $34 \%$ and $90 \%$ quenching, respectively, at these ratios (Fig. 8, Table 2), demonstrating an AQM factor of 2.

$\mathrm{UV}-\mathrm{Vis}$ titration experiments confirmed that these results were the consequence of an increase in binding constant from $K_{\mathrm{a}}=3 \times 10^{5} \mathrm{M}^{-1}$ to $K_{\mathrm{a}}=8 \times 10^{5} \mathrm{M}^{-1}$ in the presence of the axial ligand tbpy. In energy terms this corresponds to a $\Delta \Delta G$ of only $-3 \mathrm{~kJ} \mathrm{~mol}^{-1}$, which does however demonstrate the first example of an allosteric effect being employed in the selfassembly of synthetic photo-active systems.

The reverse approach, where tbpy was added to a $1: 1$ mixture of $\mathbf{Z n P}$ and AuP-bipy in $\mathrm{CHCl}_{3} / \mathrm{CH}_{3} \mathrm{CN}=1: 1(\mathrm{v} / \mathrm{v})$ resulted in an increase in quenching of $14 \%$ (Fig. 9).

Before fluorescence quenching experiments were attempted on the gold porphyrin with four attached guest sites AuP(bipy) $)_{\text {, }}$ it was first tested whether four zinc porphyrin clips could be complexed to this molecule. ${ }^{1} \mathrm{H}$ NMR experiments of a mixture of $4: 1 \mathbf{Z n P} / \mathbf{A u P}$-(bipy) a $_{4}$ at a concentration of $10^{-3}$ $\mathrm{M}$ in $\mathrm{CDCl}_{3} / \mathrm{CD}_{3} \mathrm{CN}=1: 1(\mathrm{v} / \mathrm{v})$ did not show the presence of uncomplexed bipyridinium units, indicating a complete formation of the 4 : 1 host-guest complex. Unfortunately, the crown ether proton signals of $\mathbf{Z n P}$ were significantly broadened, rendering assignment impossible. Therefore the proton signals of the bipyridine guest were scarcely visible. From the peaks that could be interpreted, a similar binding geometry as for the complexes of $\mathbf{Z n P}$ with P-bipy was deduced (Table 1).

The quenching behaviour of compound AuP-(bipy) $)_{4}$ is interesting. Addition of 0.25 eq of AuP-(bipy) $\mathbf{~}_{\mathbf{4}}$ to $\mathbf{Z n P}$ results in a quenching of the fluorescence of the latter porphyrin of $20 \%$, similar as in the case of the complex of $\mathbf{Z n P}$ with AuPbipy at a host-guest ratio of $1: 1$ (Fig. 8, Table 2). The total quenching of $\mathbf{Z n P}$ fluorescence after the addition of 2.5 eq of AuP-(bipy) 4 $_{\mathbf{4}}$ adds up to $88 \%$, a little higher than for the ZnPAuP-bipy complex. The calculated binding constant between

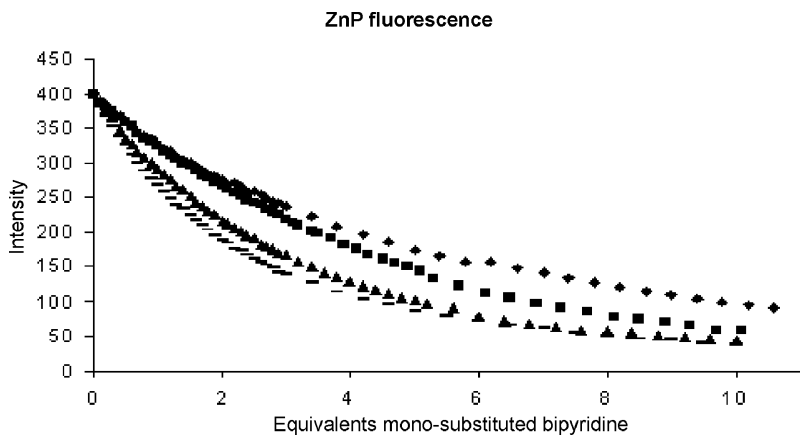

Fig. 8 Fluorescence quenching for $\mathrm{ZnP}$ by AuP-bipy and AuP-(bipy) in the absence of and in the presence of 500 eq tbpy. $\mathrm{CHCl}_{3} / \mathrm{CH}_{3} \mathrm{CN}=$ $1: 1(\mathrm{v} / \mathrm{v}) . T=298 \mathrm{~K}$. Excitation $=426 \mathrm{~nm}$. Emission $=605 \mathrm{~nm}$. $[\mathrm{ZnP}]=10^{-6} \mathrm{M}$. $\mathbf{Z n P}+$ AuP-bipy; $-\mathbf{Z n P} /$ tbpy + AuP-bipy; $\triangle \mathrm{ZnP}+\mathrm{AuP}_{-(\text {bipy) }} ; \mathbf{Z} \mathbf{Z n P} /$ tbpy + AuP-(bipy) . $_{4}$.

ZnP and AuP-(bipy) $)_{4}, K_{\mathrm{a}}=7 \times 10^{5} \mathrm{M}^{-1}$, is also a little higher than the binding constant between $\mathbf{Z n P}$ and AuP-bipy $\left(K_{\mathrm{a}}=\right.$ $3 \times 10^{5} \mathrm{M}^{-1}$ ).

Repetition of this titration in the presence of 500 eq tbpy in $\mathrm{CHCl}_{3} / \mathrm{CH}_{3} \mathrm{CN}=1: 1(\mathrm{v} / \mathrm{v})$ did not result in an increase in fluorescence quenching. At a host-guest ratio of 1 : 1 (AuP(bipy) $\mathbf{4} / \mathbf{Z n P}=1: 4$ ), a fluorescence quenching of $18 \%$ was observed and after the addition of 2.5 eq of AuP-(bipy) $\mathbf{y}_{\mathbf{4}}$ the total quenching of $\mathbf{Z n P}$ fluorescence amounted to $83 \%$. This is in both cases a little lower than observed for the titration experiment in the absence of tbpy, demonstrating a negative cooperative effect and an AQM factor of 0.9 (Fig. 8, Table 2). The binding constant that was calculated from these titration experiments is also slightly lower than that for the AuP-bipy/ ZnP/tbpy-system, namely $K_{\mathrm{a}}=4 \times 10^{5} \mathrm{M}^{-1}$.

The reverse approach of adding tbpy to a $4: 1$ mixture of ZnP and AuP-(bipy) 4 $_{4}$ resulted in only 10\% extra quenching (Fig. 9). This value is equal to the quenching observed for the addition of tbpy to $\mathbf{Z n P}$ in the absence of any guest molecules (Table 2). We ascribe this observed inability of tbpy to allosterically magnify the amount of host-guest complex in solution to steric hindrance around the central porphyrin, which increases in the order ((AuP-bipy)-ZnP) $<$ ((AuPbipy)-ZnP-tbpy) $\left.<\left((\text { AuP-(bipy })_{4}\right)-(Z n P)_{4}\right)<\left((\text { AuP-(bipy })_{4}\right)-$

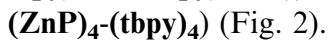

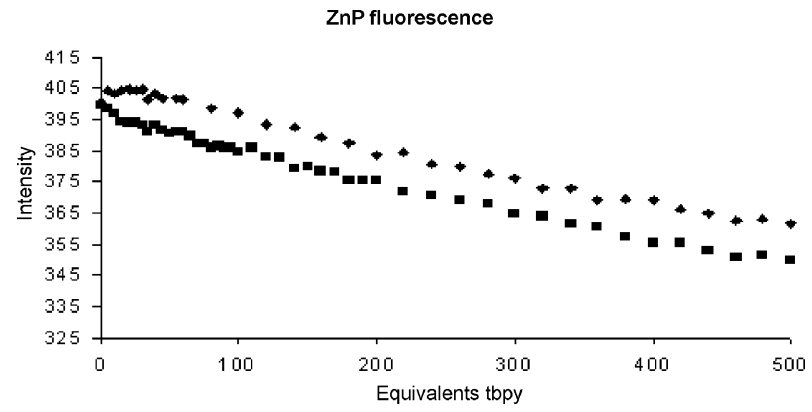

Fig. 9 Fluorescence quenching for $\mathrm{ZnP}$ by AuP-bipy and AuP-(bipy) during addition of 500 eq tbpy. $\mathrm{CHCl}_{3} / \mathrm{CH}_{3} \mathrm{CN}=1: 1(\mathrm{v} / \mathrm{v}) . T=298$ $\mathrm{K}$. Excitation $=426 \mathrm{~nm}$. Emission $=605 \mathrm{~nm}$. $[\mathbf{Z n P}]=[$ AuP-bipy $]=$ $10^{-6}$ M. [AuP-(bipy) $\left.)_{4}\right]=2.5 \times 10^{-5}$ M. $\mathbf{Z n P} /$ AuP-bipy + tbpy; $\mathrm{ZnP} /$ AuP-(bipy) $)_{4}+$ tbpy. 


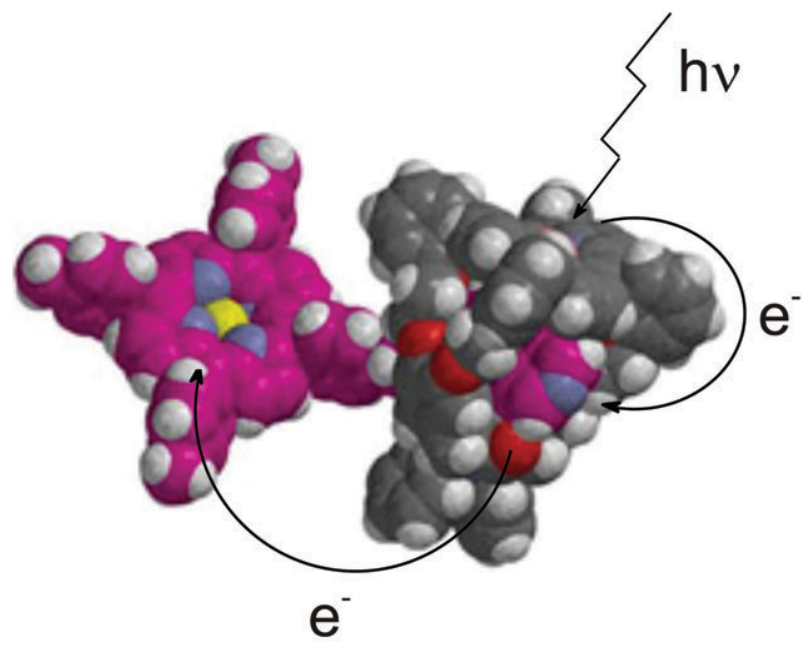

Fig. 10 Schematic representation of possible ET processes in [2]pseudo-rotaxane (AuP-bipy)-ZnP.

To investigate the effect of the gold ion in the central porphyrin of AuP-bipy and AuP-(bipy), we have compared the reduction potentials of the mono-substituted bipyridinium unit with the reduction potential of gold(III) porphyrins.

Milgrom et al. determined a reduction potential in DMF for ZnP-(bipy) 4 $-1.77 \mathrm{~V} v s$. $\mathrm{Fc}^{+/ 0}{ }^{11}$ Gold porphyrins usually have a reduction potential around $-1.2 \mathrm{~V} v s . \mathrm{Fc}^{+/ 0}$, depending on the solvent and the substituents on the porphyrin. ${ }^{14}$ One would expect that also in this solvent system the reduction potential of a gold(III) porphyrin is significantly less negative than that of appended mono-substituted bipyridine. This would mean that the gold porphyrin is the better candidate for electron acceptance. However, since electron transfer (ET) to the mono-substituted bipyridinium guest as well as ET to the gold porphyrin has to occur 'through space', the rate of ET is proportional to $\exp (-2 R / L)(R=$ donor-acceptor separation; $L=$ Van der Waals radius). The PM3 model of (AuPbipy)-ZnP gives an indication of the distance between the zinc ion and the positively charged nitrogen atom and between the zinc ion and the gold ion, namely $5 \AA$ and $20 \AA$, respectively. In view of these distances, a direct ET from the zinc porphyrin to the gold porphyrin will be negligible compared to ET with the mono-substituted bipyridine as electron acceptor. However, a successive charge shift from the mono-substituted bipyridine unit to the gold porphyrin should be possible and is probable (Fig. 10). The positively charged nitrogen atom and the central porphyrin gold ion are only $18 \AA$ apart, and the studies on zinc tetraviologen complexes which were mentioned earlier, have already shown that ET across this distance is possible. Emission spectra of the [2]-pseudo-rotaxane (AuP-bipy)-ZnP recorded at $77 \mathrm{~K}$ revealed no phosphorescence from the gold porphyrin after excitation of the zinc porphyrin. Energy transfer to the gold porphyrin can therefore be ruled out.

\section{Experimental}

UV-Vis spectra were recorded on a Varian Cary $50 \mathrm{UV}-\mathrm{V}$ is spectrophotometer. Fluorescence titrations were performed on a Perkin Elmer luminescence Ls50B spectrometer. ${ }^{1} \mathrm{H}$ NMR spectra were obtained on a Varian Unity Inova $400 . \mathrm{CHCl}_{3}$ was distilled over $\mathrm{CaCl}_{2}$ and $\mathrm{CH}_{3} \mathrm{CN}$ was distilled over $\mathrm{CaH}_{2}$ before use. $\mathbf{Z n P}$ and $\mathbf{M}$-bipy were synthesised according to literature procedures. ${ }^{9 a, 16}$

\section{(5-(4,4'-Bipyridinium)pentoxy)benzene hexafluorophosphate (P-bipy)}

To dibromopentane $(14.5 \mathrm{ml}, 106 \mathrm{mmol})$ and $\mathrm{K}_{2} \mathrm{CO}_{3}(3 \mathrm{~g})$ in DMF (70 ml) was added phenol $(1 \mathrm{~g}, 10.6 \mathrm{mmol})$, after which the mixture was refluxed under a $\mathrm{N}_{2}$ atmosphere for $3 \mathrm{~h}$. After cooling and filtration all liquids were distilled off under reduced pressure. The remaining solid was dissolved in diethyl ether $(20 \mathrm{ml})$ and this solution was added drop-wise to methanol $(200 \mathrm{ml})$. The resulting precipitate was filtered off, washed with methanol and purified by column chromatography (silica; $n$-hexane $/ \mathrm{CH}_{2} \mathrm{Cl}_{2}=7: 3(\mathrm{v} / \mathrm{v})$ ) and the product was dried in vacuo. A portion of the resulting white solid (2.32 g, $9.55 \mathrm{mmol}$ ) was dissolved in DMF (50 ml) and 4,4'bipyridine was added (5.9 gr, $38.2 \mathrm{mmol}$ ). This mixture was stirred under a $\mathrm{N}_{2}$ atmosphere at $90{ }^{\circ} \mathrm{C}$ for $72 \mathrm{~h}$. After concentration of the solution under reduced pressure, it was added to a saturated $\mathrm{NH}_{4} \mathrm{PF}_{6}$ (aq) solution $(200 \mathrm{ml})$. The precipitate was filtered off, washed with water and purified by column chromatography (silica; $\mathrm{CH}_{2} \mathrm{Cl}_{2} / \mathrm{MeOH} / \mathrm{MeNO}_{2}=$ $6: 1: 1$ ) and the product was dried in vacuo. Yield: $70 \%$ of a white solid.

${ }^{1} \mathrm{H}$ NMR $\left(\mathrm{CDCl}_{3} / \mathrm{CD}_{3} \mathrm{CN}=1: 1(\mathrm{v} / \mathrm{v}), 300.13 \mathrm{MHz}, 25\right.$ $\left.{ }^{\circ} \mathrm{C}\right): \delta=8.79\left(\mathrm{~d}, 2 \mathrm{H}, \mathrm{Py} H-2,6,{ }^{3} J=6.3 \mathrm{~Hz}\right), 8.73(\mathrm{~d}, 2 \mathrm{H}$, Py $H-$ $\left.2^{\prime}, 6^{\prime},{ }^{3} J=6.9 \mathrm{~Hz}\right), 8.26\left(\mathrm{~d}, 2 \mathrm{H}, \mathrm{Py} H-3,5,{ }^{3} J=5.1 \mathrm{~Hz}\right), 7.71$ $\left(\mathrm{d}, 2 \mathrm{H}, \mathrm{Py} H-3^{\prime}, 5^{\prime},{ }^{3} \mathrm{~J}=6.3 \mathrm{~Hz}\right), 7.24\left(\mathrm{t}, 2 \mathrm{H}, \mathrm{Ar} H-3,5,{ }^{3} J=6.6\right.$ $\mathrm{Hz}), 6.86(\mathrm{~m}, 3 \mathrm{H}, \mathrm{Ar} H-2,4,6), 4.56\left(\mathrm{t}, 2 \mathrm{H}, \mathrm{N}-\mathrm{CH}_{2},{ }^{3} \mathrm{~J}=7.6\right.$ $\mathrm{Hz}), 3.97\left(\mathrm{t}, 2 \mathrm{H}, \mathrm{O}-\mathrm{CH}_{2},{ }^{3} \mathrm{~J}=7.9 \mathrm{~Hz}\right), 2.07(\mathrm{~m}, 2 \mathrm{H}, \mathrm{N}-\mathrm{C}-$ $\left.\mathrm{CH}_{2}\right), 1.85\left(\mathrm{~m}, 2 \mathrm{H}, \mathrm{O}-\mathrm{C}-\mathrm{CH}_{2}\right), 1.57$ (m, 2H, C-CH $\left.-\mathrm{C}\right)$. FAB-MS: $m / z=319$ [P-bipy $\left.-\mathrm{PF}_{6}\right]^{+}$.

\section{3,5-Di-tert-butyl-1-(5-(4,4' -bipyridinium)pentoxy)benzene hexafluorophosphate (T-bipy)}

This compound was synthesised analogous to P-bipy, but 3,5di-tert-buylphenol $(2.2 \mathrm{~g}, 10.6 \mathrm{mmol})$ was used instead of phenol.

${ }^{1} \mathrm{H}$ NMR $\left(\mathrm{CDCl}_{3} / \mathrm{CD}_{3} \mathrm{CN}=1: 1(\mathrm{v} / \mathrm{v}), 300.13 \mathrm{MHz}\right.$, $\left.25^{\circ} \mathrm{C}\right): \delta=8.85\left(\mathrm{~d}, 2 \mathrm{H}, \mathrm{Py} H-2,6,{ }^{3} \mathrm{~J}=6.3 \mathrm{~Hz}\right), 8.73(\mathrm{~d}, 2 \mathrm{H}$, Py $\left.H-2^{\prime}, 6^{\prime},{ }^{3} J=6.9 \mathrm{~Hz}\right), 8.26\left(\mathrm{~d}, 2 \mathrm{H}, \mathrm{Py} H-3,5,{ }^{3} J=5.1 \mathrm{~Hz}\right)$, 7.71 (d, 2H, Py $\left.H-3^{\prime}, 5^{\prime},{ }^{3} J=6.3 \mathrm{~Hz}\right), 6.99$ (s, 1H, ArH-4), 6.69 (s, 2H, ArH-2,6), 4.58 (t, 2H, N-CH,$\left.{ }^{3} \mathrm{~J}=7.6 \mathrm{~Hz}\right), 3.98$ $\left(\mathrm{t}, 2 \mathrm{H}, \mathrm{O}-\mathrm{CH}_{2},{ }^{3} \mathrm{~J}=7.9 \mathrm{~Hz}\right), 2.10\left(\mathrm{~m}, 2 \mathrm{H}, \mathrm{N}-\mathrm{C}-\mathrm{CH}_{2}\right), 1.85$ $\left(\mathrm{m}, 2 \mathrm{H}, \mathrm{O}-\mathrm{C}-\mathrm{CH}_{2}\right), 1.60\left(\mathrm{~m}, 2 \mathrm{H}, \mathrm{C}-\mathrm{CH}_{2}-\mathrm{C}\right), 1.26(\mathrm{~s}, 18 \mathrm{H}$, $\mathrm{CH}_{3}$ ). FAB-MS: $m / z=431\left[\text { T-bipy }-2 \mathrm{PF}_{6}\right]^{+}$.

\section{5-(4-(5-(4,4'-Bipyridinium)-1-pentoxy)phenyl)-10,15,20-tri} (4-toluyl) gold(III) porphyrin dihexafluorophosphate (AuP-bipy)

The free base compound was synthesised according to a literature procedure. ${ }^{12 a, b}$ This compound $(100 \mathrm{mg}, 96 \mu \mathrm{mol})$ was dissolved in acetic acid $(60 \mathrm{ml})$ and $\mathrm{KAuCl}_{4}(363 \mathrm{mg}, 0.96$ mmol) and NaOAc (31 mg, $378 \mu \mathrm{mol})$ were added. The mixture was purged with $\mathrm{N}_{2}$ for $30 \mathrm{~min}$ and then refluxed under a $\mathrm{N}_{2}$ atmosphere and under exclusion of light for 7 days. 
After cooling, the solvent was evaporated and the remaining solid was dissolved in $\mathrm{CH}_{2} \mathrm{Cl}_{2}(40 \mathrm{ml})$. This solution was washed with an aqueous $10 \% \quad \mathrm{Na}_{2} \mathrm{CO}_{3}$ solution. After evaporation of the organic layer, the residue was dissolved in DMF $(5 \mathrm{ml})$ and this solution was added drop-wise, with vigorous stirring, to a saturated aqueous $\mathrm{NH}_{4} \mathrm{PF}_{6}$ solution. The precipitate was filtered off, washed with water and methanol and dried in vacuo. Purification by column chromatography (silica, $\mathrm{CH}_{2} \mathrm{Cl}_{2} / \mathrm{CH}_{3} \mathrm{OH} / \mathrm{CH}_{3} \mathrm{NO}_{2}=6: 1: 1$ ) yielded the desired product in $25 \%$ yield as an orange solid.

${ }^{1} \mathrm{H}$ NMR $\left(\mathrm{CD}_{2} \mathrm{Cl}_{2}, 400.15 \mathrm{MHz}, 25{ }^{\circ} \mathrm{C}\right): \delta=9.34$ (bs, $8 \mathrm{H}$, $\beta$-pyrrole $H$ ), 8.97 (d, 2H, Py $\left.H-2,6,{ }^{3} J=6.5 \mathrm{~Hz}\right), 8.92$ (d, 2H, Py $\left.H-2^{\prime}, 6^{\prime},{ }^{3} J=6.9 \mathrm{~Hz}\right), 8.40\left(\mathrm{~d}, 2 \mathrm{H}, \mathrm{Py} H-3,5,{ }^{3} J=6.7 \mathrm{~Hz}\right)$, 8.10 (d, 2H, ArH-2,6 meta to $\mathrm{O}\left(\mathrm{CH}_{2}\right)_{5}$-bipy, $\left.{ }^{3} \mathrm{~J}=7.7 \mathrm{~Hz}\right), 8.08$ (d, $\left.6 \mathrm{H}, \operatorname{Ar} H-2,6,{ }^{3} \mathrm{~J}=7.5 \mathrm{~Hz}\right), 7.92\left(\mathrm{~d}, 2 \mathrm{H}, \mathrm{Py} H-3^{\prime}, 5^{\prime},{ }^{3} \mathrm{~J}=\right.$ $5.8 \mathrm{~Hz}), 7.68\left(\mathrm{~d}, 6 \mathrm{H}, \mathrm{Ar} H-3,5,{ }^{3} \mathrm{~J}=8.2 \mathrm{~Hz}\right), 7.37(\mathrm{~d}, 2 \mathrm{H}, \mathrm{Ar} H-$ 3,5 ortho to $\mathrm{O}\left(\mathrm{CH}_{2}\right)_{5}$-bipy, $\left.{ }^{3} \mathrm{~J}=8.7 \mathrm{~Hz}\right), 4.75\left(\mathrm{t}, 8 \mathrm{H}, \mathrm{N}-\mathrm{CH}_{2}\right.$, $\left.{ }^{3} \mathrm{~J}=7.4 \mathrm{~Hz}\right), 4.40\left(\mathrm{t}, 8 \mathrm{H}, \mathrm{O}-\mathrm{CH}_{2},{ }^{3} \mathrm{~J}=6.9 \mathrm{~Hz}\right), 2.73(\mathrm{~s}, 9 \mathrm{H}$, $\left.\mathrm{CH}_{3}\right), 2.38\left(\mathrm{~m}, 2 \mathrm{H}, \mathrm{N}-\mathrm{C}-\mathrm{CH}_{2}\right), 2.20\left(\mathrm{~m}, 2 \mathrm{H}, \mathrm{O}-\mathrm{C}-\mathrm{C} H_{2}\right), 1.95$ (m, 2H, C-C $\left.\mathrm{H}_{2}-\mathrm{C}\right)$. UV-Vis $\left(\mathrm{CH}_{2} \mathrm{Cl}_{2}\right): 415$, 525. MALDITOF: $m / z=1238$ [AuP-bipy $\left.-\mathrm{PF}_{6}\right]^{+}$.

5,10,15,20-Tetrakis(4-(5-(4,4'-bipyridinium)-1-pentoxy)phenyl) gold(III) porphyrin penta(hexafluorophosphate) (AuP-(bipy) 4 )

The free base analogue was synthesised according to a literature procedure. ${ }^{12 a, b}$ Gold was inserted analogous to described for the synthesis of AuP-bipy, also starting with $100 \mathrm{mg}$ (63 $\mu \mathrm{mol})$ free base compound. After evaporation of acetic acid, the mixture was dissolved in DMF $(5 \mathrm{ml})$ and added drop-wise to a saturated aqueous $\mathrm{NH}_{4} \mathrm{PH}_{6}$ solution. The precipitate was washed with water and methanol. It was then dissolved in $\mathrm{CH}_{3} \mathrm{CN}(5 \mathrm{ml})$, after which insoluble material was filtered off. The solvent was evaporated and the remaining product was dried in vacuo. Yield: $30 \%$ of an orange solid.

${ }^{1} \mathrm{H}$ NMR $\left(\mathrm{CD}_{3} \mathrm{CN}, 400.15 \mathrm{MHz}, 25^{\circ} \mathrm{C}\right): \delta=9.30(\mathrm{~s}, 8 \mathrm{H}, \beta-$ pyrrole $H$ ), 8.84 (d, $8 \mathrm{H}$, Py $\left.H-2,6,{ }^{3} J=6.4 \mathrm{~Hz}\right), 8.80(\mathrm{bs}, 8 \mathrm{H}$, Рy $\left.H-2^{\prime}, 6^{\prime}\right), 8.36\left(\mathrm{~d}, 8 \mathrm{H}, \mathrm{Py} H-3,5,{ }^{3} J=6.8 \mathrm{~Hz}\right), 8.13(\mathrm{~m}, 8 \mathrm{H}$, $\mathrm{Ar} H-2,6), 7.79$ (d, 8H, PyH-3' $\left.5^{\prime},{ }^{3} J=4.6 \mathrm{~Hz}\right), 7.41$ (d, 8H, $\left.\mathrm{Ar} H-3,5,{ }^{3} \mathrm{~J}=8.6 \mathrm{~Hz}\right), 4.67\left(\mathrm{t}, 8 \mathrm{H}, \mathrm{N}-\mathrm{CH}_{2},{ }^{3} \mathrm{~J}=7.6 \mathrm{~Hz}\right), 4.31$ $\left(\mathrm{t}, 8 \mathrm{H}, \mathrm{O}-\mathrm{CH}_{2},{ }^{3} \mathrm{~J}=6.1 \mathrm{~Hz}\right), 2.20\left(\mathrm{~m}, 8 \mathrm{H}, \mathrm{N}-\mathrm{C}-\mathrm{CH}_{2}\right), 2.04$ $\left(\mathrm{m}, 8 \mathrm{H}, \mathrm{O}-\mathrm{C}-\mathrm{CH}_{2}\right), 1.70\left(\mathrm{~m}, 8 \mathrm{H}, \mathrm{C}-\mathrm{CH}_{2}-\mathrm{C}\right)$. UV-Vis $\left(\mathrm{CH}_{3} \mathrm{CN}\right): 419$, 523. MALDI-TOF: $m / z=2354$ [AuP-(bipy) $\left.-\mathrm{PF}_{6}\right]^{+}$.

UV-Vis and fluorescence titration experiments were carried out following the standard methods reported earlier by our group. ${ }^{8 b}$ Also the calculation of binding constants from these titration experiments has been carried out with the method published before. ${ }^{8 b}$

\section{Conclusions}

We have reported in this paper the first example of employing allosteric interactions to enhance electron transfer in a pseudorotaxane system. Binding of an axial ligand (tbpy) to an electron donating zinc porphyrin $(\mathbf{Z n P})$, has been shown to increase the complexation strength of $\mathbf{Z n P}$ to a series of electron accepting mono-substituted bipyridine guests, result- ing in a more pronounced electron transfer process after excitation of the zinc porphyrin. The allosteric increase in the association constant between the $\mathbf{Z n P}$ host and the monosubstituted bipyridine guest in the presence of tbpy is evidenced by a more efficient quenching of the zinc porphyrin fluorescence by the guest, relative to the same sample in the absence of the axial ligand. Following electron transfer to the bipyridine guest, charge-shift to an appended gold porphyrin is tentatively suggested. Future studies are aimed at the detailed investigation of the precise electron transfer processes and the effect of allosterism upon it.

\section{Acknowledgements}

We would like to thank Prof. dr ir R. A. J. Janssen and Dr S. C. J. Meskers from the Technical University Eindhoven for their assistance with the fluorescence measurements at $77 \mathrm{~K}$. The Council for the Chemical Sciences of the Netherlands Organization for Scientific Research (CW-NWO) is acknowledged for financial support to J.A.A.W.E. (Veni grant) and A.E.R. (Vidi grant). P.T. thanks the University of Sydney for a SESQUI Fellowship.

\section{References}

1 J. Deisenhofer and J. R. Norris, The Photosynthetic Reaction Center, Academic Press, San Diego, California, 1993.

2 J. D. Rawn, Biochemistry, Neil Patterson Publishers, Burlington, North Carolina, 1989.

3 (a) G. McLendon and R. Hake, Chem. Rev., 1992, 92, 481; (b) M. R. Wasielewski, Chem. Rev., 1992, 92, 435; (c) D. Gust, A. T. Moore and A. L. Moore, Acc. Chem. Res., 1993, 26, 198; (d) H. Hurreck and M. Huber, Angew. Chem., Int. Ed. Engl., 1995, 34, 849; (e) A. Harriman and J.-P. Sauvage, Chem. Soc. Rev., 1996, 25, 41.

4 (a) K. D. Jordan and M. N. Paddon-Row, Chem. Rev., 1992, 92, 395; (b) M.-J. Blanco, M. Consuelo Jiménez, J.-C. Chambron, V. Heitz, M. Linke and J.-P. Sauvage, Chem. Soc. Rev., 1999, 28, 293; (c) F. Diederich and M. Gómez-López, Chem. Soc. Rev., 1999, 28, 293; (d) F. D. Lewis, R. L. Letsinger and M. R. Wasielewski, Acc. Chem. Res., 2001, 34, 159; (e) L. Flamigni, F. Barigelletti, N. Armaroli, J.-P. Collin, I. M. Dixon, J.-P. Sauvage and J. A. G. Williams, Coord. Chem. Rev., 1999, 190-192, 671; (f) S. Fukuzumi, K. Ohkubo, H. Imahori, J. Shao, Z. Ou, G. Zheng, Y. Chen, R. K. Pandey, M. Fujistuka, O. Ito and K. M. Kadish, J. Am. Chem. Soc., 2001, 123, 10676; (g) I.-W. Hwang, M. Park, T. K. Ahn, Z. S. Yoon, D. M. Ko, D. Kim, F. Ito, Y. Ishibashi, S. R. Khan, Y. Nagasawa, H. Miyasaka, C. Ikeda, R. Takahashi, K. Ogawa, A. Satake and Y. Kobuke, Chem.-Eur. J., 2005, 11, 3753.

5 (a) D. M. Guldi and H. Imahori, J. Porphyrins Phthalocyanines, 2004, 8, 976, and references therein; (b) M.-S. Choi, T. Yamazaki, I. Yamazaki and T. Aida, Angew. Chem., Int. Ed., 2004, 43, 150, and references therein.

6 C. A. Hunter and R. K. Hyde, Angew. Chem., Int. Ed. Engl., 1996, 35, 1936.

7 J. Monod, J. Wymann and J. P. Changeux, J. Mol. Biol., 1965, 12, 88.

8 (a) P. Thordarson, E. J. A. Bijsterveld, J. A. A. W. Elemans, P. Kasák, R. J. M. Nolte and A. E. Rowan, J. Am. Chem. Soc., 2003, 125, 1186; (b) P. Thordarson, R. G. E. Coumans, J. A. A. W. Elemans, P. J. Thomassen, J. Visser, A. E. Rowan and R. J. M. Nolte, Angew. Chem., Int. Ed., 2004, 43, 4755.

9 (a) A. E. Rowan, P. P. M. Aarts and K. W. M. Koutstaal, Chem. Commun., 1998, 611; (b) J. A. A. W. Elemans, M. B. Claase, P. P. M. Aarts, A. E. Rowan, A. P. H. J. Schenning and R. J. M. Nolte, J. Org. Chem., 1999, 64, 7009.

10 (a) J. A. A. W. Elemans, E. J. A. Bijsterveld, A. E. Rowan and R. J. M. Nolte, Chem. Commun., 2000, 2443; (b) P. Thordarson, 
E. J. A. Bijsterveld, A. E. Rowan and R. J. M. Nolte, Nature, 2003, 424, 915.

11 G. Blondeel, D. De Keukeleire, A. Harriman and L. R. Milgrom, Chem. Phys. Lett., 1985, 118, 77.

12 (a) L. R. Milgrom, J. Chem. Soc., Perkin Trans. 1, 1983, 2535; (b) A. Harriman, G. Porter and A. Wilowska, J. Chem. Soc., Faraday Trans. 2, 1984, 80, 191; (c) A. Harriman, Inorg. Chim. Acta, 1984, 88, 213; (d) J. D. Batteas, A. Harriman, Y. Kanda, N. Mataga and A. K. Nowak, J. Am. Chem. Soc., 1990, 112, 126; (e) S. Noda, H. Hosono, I. Okura, Y. Yamamoto and Y. Inoue, J. Chem. Soc., Faraday Trans., 1990, 86, 811; (f) J. Hirota and I. Okura, J. Phys. Chem., 1993, 97, 6867; (g) H. Hosono and M. Kaneko, J. Chem. Soc., Faraday Trans., 1997, 93, 1313.

13 (a) S. Prathapan, T. E. Johnson and J. S. Lindsey, J. Am. Chem. Soc., 1993, 115, 7519; (b) J. Seth, V. Palaniappan, T. E. Johnson, S. Prathapan, J. S. Lindsey and D. F. Bocian, J. Am. Chem. Soc.,
1994, 116, 10578; (c) J.-S. Hsiao, B. P. Krueger, R. W. Wagner, T. E. Johnson, J. K. Delaney, D. C. Mauzerall, G. R. Fleming, J. S. Lindsey, D. F. Bocian and R. J. Donohoe, J. Am. Chem. Soc., 1996, 118, 11181

14 (a) A. M. Brun, A. Harriman, V. Heitz and J.-P. Sauvage, J. Am. Chem. Soc., 1991, 113, 8657; (b) M. Linke, J.-C. Chambron, V. Heitz, J.-P. Sauvage, S. Encinas, F. Barigelletti and L. Flamigni, J. Am. Chem. Soc., 2000, 122, 11834; (c) K. Kilså, J. Kajanus, A. N. Macpherson, J. Mårtensson and B. Albinsson, J. Am. Chem. Soc., 2001, 123, 3069; (d) S. Fukuzumi, K. Ohkubo, W. E. Z. Ou, J. Shao, K. M. Kadish, J. A. Hutchison, K. P. Ghiggino, P. J. Sintic and M. J. Crossley, J. Am. Chem. Soc., 2003, 125, 14984.

15 A. M. Brun, S. J. Atherton, A. Harriman, V. Heitz and J.-P. Sauvage, J. Am. Chem. Soc., 1992, 114, 4632.

16 Y. S. Park, E. J. Lee, Y. S. Chun, Y. D. Yoon and K. B. Yoon, J. Am. Chem. Soc., 2002, 24, 7123 . 